JHR

35,6

540

Received 5 December 2019

Revised 19 March 2020

20 April 2020

Accepted 25 May 2020

\section{Risk factors associated with hypertension in Bhutan: findings from the National Health Survey}

\author{
Tashi Dendup \\ Faculty of the Arts, Social Sciences and Humanities, School of Health and Society, \\ University of Wollongong, Wollongong, Australia, and \\ Pandup Tshering and Tandin Dorji \\ Ministry of Health, Royal Government of Bhutan, Thimphu, Bhutan
}

\begin{abstract}
Purpose - This study examined the risk factors associated with hypertension in Bhutan.

Design/methodology/approach - The cross-sectional data of 30,889 adults from the National Health Survey of Bhutan was used in this study. Multivariable regression accounting for the complex survey design was performed to identify the risk factors. The backward elimination approach was applied in the multivariable analysis.

Findings - The prevalence of hypertension was $17 \%$. Increasing age, being female, being previously married, higher wealth status, past alcohol use, having diabetes, loneliness, health service use and low vegetable intake was associated with increased hypertension risk, whereas, higher education level, being employed and residing in the eastern region was associated with reduced risk. Age, gender, education, wealth status, diabetes status, loneliness and health service use were common factors in all the regions. Marital status and vegetable intake were associated with hypertension in the western and central regions, and alcohol use in the eastern and central regions.

Originality/value - Affecting around one-sixth of the population, hypertension is a significant public health problem in Bhutan. Interventions to improve health education and access, motivate healthy lifestyles, and reduce harmful alcohol use, and strategies to create health-promoting social and built environments are needed to curb the hypertension epidemic and its consequences.
\end{abstract}

Keywords Hypertension, Risk factors, Loneliness, Blood pressure, Bhutan

Paper type Research paper

\section{Introduction}

Responsible for around $9.4 \mathrm{~m}$ deaths annually, hypertension or high blood pressure is a leading cause of morbidity and mortality worldwide [1, 2]. Hypertension can lead to heart attack, heart failure, stroke, kidney failure and blindness if left untreated and uncontrolled [1]. The global prevalence of increased blood pressure among persons aged more than 18 years was estimated to be $22 \%$ in 2015 with higher rates in low- and middle-income countries than in high-income countries [3]. In the South Asian Association for Regional Cooperation

(C) Tashi Dendup, Pandup Tshering and Tandin Dorji. Published in Journal of Health Research. Published by Emerald Publishing Limited. This article is published under the Creative Commons Attribution (CC BY 4.0) licence. Anyone may reproduce, distribute, translate and create derivative works of this article (for both commercial and non-commercial purposes), subject to full attribution to the original publication and authors. The full terms of this licence may be seen at http://creativecommons. org/licences/by/4.0/legalcode

The authors would like to thank the Ministry of Health of Bhutan for granting access to the $2012 \mathrm{NHS}$ dataset. We also thank all the participants of the 2012 NHS.

Ethics statement: Ethical approval was granted by the Bhutan Research Ethics Board of Health for the conduct of this study.

Funding: This study used a secondary dataset, and no funding was received.

Conflict of interest: The authors have no conflicts of interest associated with the material presented in this paper. 
(SAARC) region, the prevalence of hypertension ranges from a low of $13.6 \%$ to as high as $47.9 \%$ [4]. Claiming around 1.5m lives annually, hypertension is the leading cause of death in this region [5]. Blood pressure is described as high or increased when the systolic blood pressure is equal to or above $140 \mathrm{mmHg}$ and/or a diastolic blood pressure equal to or above $90 \mathrm{mmHg}$ [1]. Because the signs and symptoms are usually not evident in most people, it is referred to as the "silent killer" [1].

Bhutan is a small landlocked Himalayan country in South Asia known for its development philosophy of Gross National Happiness. The State provides health services free of cost through its health system that is built upon primary health care principles [6]. Like many countries in the region, Bhutan is also currently undergoing an epidemiological and nutritional transition, and the burden of noncommunicable diseases (NCDs) are rising [6]. As per the National Health Survey (NHS) 2012, the prevalence of hypertension was 16\% [7]. Some studies reported a prevalence of as high as $26 \%$ among individuals aged 25-74 years [8] to around $36 \%$ among those aged 18-69 years [9]. The administrative data also show an increasing incidence of hypertension from 310 per 10,000 population in 2009 [10] to 458 in 2015 [11]. The incidence was reported to be 278 per 10,000 in 2017 [11]. The data may not capture all the cases in the country and thus may not reflect the actual burden. The likely increase is corroborated by hospital-based data showing an increased use and expense of anti-hypertensive drugs and the rise in referrals for cardiovascular and related diseases $[6,12]$. Similarly, the burden of NCDs depicts a worrying trend for which hypertension is a major cause [6]. Intensified efforts are needed to control the epidemic and to prevent the devastating impact of hypertension in Bhutan.

There is a paucity of epidemiological data on the factors influencing hypertension in Bhutan. National surveys show a high prevalence of behavioral risk factors such as alcohol and tobacco use, excess salt consumption, low consumption of fruits and vegetables and obesity $[7,9]$. Being female, with a low income, older in age, with a history of hypertension and the number of monkhood years were identified as risk factors of hypertension [7, 8, 13]. However, these studies were conducted in a specific population precluding generalizability and/or do not provide a comprehensive analysis of the risk factors determining hypertension. A better understanding of the risk factors influencing hypertension can help identify the population at risk and areas for interventions essential to inform targeted policies aimed to control the hypertension epidemic. We examined the demographic, socioeconomic, health and behavioral factors associated with hypertension in Bhutan using the NHS dataset.

\section{Methods}

Study data

This study used the nationally representative dataset of the NHS carried out in 2012 that covered all the 20 districts in Bhutan [7]. The survey adapted the methodology and questionnaires from the global demographic and health surveys to suit the Bhutanese context. The primary sampling units were the urban and rural areas in each district, and the sample was selected in two stages. Villages in rural areas and blocks in the urban areas were selected, and households were then listed, sequentially numbered and selected using a circular systematic selection method. Sampling weights were calculated to account for differences in sampling fractions and the level of nonresponse. The NHS also calculated the standard error, confidence interval and design effect for selected indicators to assess the efficiency of sample design after declaring the complex sampling design. The data were collected from November 2012 until February 2013. The survey achieved a response rate of $87 \%$ for the eligible individuals aged $10-75$ years. A detailed description of the methodology and the findings of the NHS 2012 have been previously published [7]. After excluding 8,883

\section{Risk factors of hypertension in Bhutan}


JHR 35,6 observations of $<18$ years, one observation $>75$ years and 16 without information on hypertension, the final sample for this study was 30,889 .

\section{Study variables}

Responses to the question "Have you ever been told by a health professional that you have hypertension?" were used to determine hypertension status among males and females aged 18-75 years. The question on the intake of anti-hypertensive medication/therapy was only asked to those who responded positively to having hypertension to this question. For analysis purposes, those who reported having hypertension were coded one (1), and those who reported not having hypertension were coded zero (0).

The independent variables extracted were categorized as demographic, socioeconomic, geographic, health and behavioral factors. Age, gender, and marital status were included under the demographic group, while education level, work status and wealth index were placed under the socioeconomic group. The wealth index was developed using the principal component analysis [7]. The place and region of residence were grouped as geographic factors. The health factors comprised diabetes status (as told by a health professional), feeling lonely and health service use. The variable health service use was extracted from the response to whether the participants visited a health facility for any health concern during the previous 12 months. The number of days in a week a person ate fruit and vegetables, total time spent for vigorous physical activity in a week for work-related and sports/recreational/ fitness activities (categorized as $\geq 300,150-<300$, and $<150$ minutes per week) and whether they walked and bicycled to places comprised the behavioral factors. This category also included alcohol use (nondrinker, ex-drinker, $\leq 3$ days a month, 1-4 days per week and $\geq 5$ days per week), smoking and use of smokeless tobacco (such as chewing tobacco, snuff and betel quid). The questions on ever having consumed alcohol, alcohol consumption and frequency in the past 12 months were used to define the alcohol use variable.

\section{Statistical analysis}

Cross-tabulations and chi-square significance tests were conducted to assess the distribution of hypertension and the univariate associations. Since the multivariable log-binomial regression model failed to converge, Poisson regression with robust error variance was performed to examine the association between the explanatory variables and hypertension risk. The log-binomial and robust Poisson approaches were found to produce comparable estimates and standards errors, and the prevalence ratio was also easier to interpret and communicate $[14,15]$. Robust Poisson regression is a modified Poisson regression wherein variance estimates that are robust to error misspecification are obtained using a sandwich estimator [14]. The sandwich estimation helps to account for the potential overestimation of error for the relative risk in Poisson regression employed to analyze binomial data. Unadjusted and adjusted prevalence ratios along with their 95\% CIs were generated and reported.

Those variables found significant at the $10 \%$ level $(\phi$-value $<0.1)$ in the bivariate analysis were included in the multivariable analysis that was built using backward elimination to identify the significant variables. In the final model, a $p$-value of $<0.05$ was considered statistically significant. Given the large number of variables and to assess the potential joint predictive capability of variables, the backward elimination approach was used in the analysis. All of the variables were entered again one by one in the final model to reassess their effect. To account for the unequal selection probability arising from multistage sampling, sampling weights and clustering of the NHS, complex samples analysis was applied. The STATA svy command was used to analyze the data. The individual sampling weight variable, strata variable and the primary sampling unit variable provided in the dataset were specified to declare survey design using the STATA svy command set. 


\section{Results}

Of the 30,889 participants ( $46 \%$ males and $54 \%$ females), 5,216 reported having hypertension giving a weighted prevalence of $17 \%$. Table 1 presents the socioeconomic, demographic, geographic, health and behavioral characteristics of the participants and the distribution of hypertension by these characteristics. The mean age of the participants was 39 years (SD: 14.9). The majority of participants were $<45$ years of age, married, unemployed, resided in the central region and rural areas and had no formal education. Most participants used the health service, did not have diabetes and never felt lonely. A higher proportion of the participants did not eat fruits but ate vegetables (on $>5$ days a week), had inadequate or $<150$ minutes of vigorous physical activity per week but walked or bicycled to places, did not consume alcohol and never smoked.

More than $70 \%$ of those identified as hypertensive were $>35$ years of age, females $(62.6 \%)$, and $>80 \%$ with hypertension were married. $60 \%$ of those with hypertension were uneducated, and around 54\% were unemployed. Most respondents with hypertension were from more affluent households, rural areas, the central and western regions, did not have diabetes, never felt lonely and used health services. A majority of those with hypertension also did not eat fruits but ate vegetables (on 4-7 days a week), had inadequate vigorous physical activity $(53.7 \%)$ but walked or bicycled to places $(67.5 \%)$, never smoked $(82.8 \%)$ and were nondrinkers $(50.2 \%)$.

In Table 2, the bivariate unadjusted analysis showed a higher risk of having hypertension with increasing age, among females, those married and previously married, those from wealthier households, without education, not working and among residents of the western region. Those who used health service, felt lonely, had diabetes, had inadequate vigorous physical activity and did not walk/bicycle to places were former drinkers and consumed vegetables on $<4$ days a week also had a higher risk of hypertension.

In the multivariable analysis, most of the adjusted prevalence ratios were well below the levels of the corresponding unadjusted prevalence ratios. The association was reduced considerably for marital status. Age, gender and education appeared to explain a large portion of the association between marital status and hypertension. The associations for wealth index and vegetable intake slightly increased. The moderate correlation $(r<0.3)$ between wealth index and education, and vegetable intake and region of residence might have led to this small increase. Furthermore, the associations for vigorous physical activity and walk/bicycle to places were not statistically significant in the multivariable analysis.

The results showed an increased risk of having hypertension with increasing age with the greatest risk among those aged $>64$ years $(\mathrm{aPR}=3.17, p<0.001)$ than those who were $18-24$ years old. Females $(\mathrm{aPR}=1.33, p<0.001)$ were also more likely to have hypertension. Relative to those with high school and above education, the risk of hypertension among respondents with no education, primary education and with monastic and/or nonformal education was higher by $18 \%(p=0.006), 26 \%(\phi=0.001)$ and $34 \%(p<0.001)$, respectively. Furthermore, individuals who were married, previously married and those in the second and higher wealth index category had a significantly greater hypertension risk. The risk of hypertension was also higher among those who had diabetes $(\mathrm{aPR}=1.95, p<0.001)$ and used health services $(\mathrm{aPR}=1.59, p<0.001)$ compared to their counterparts. Those who were rarely $(\mathrm{aPR}=1.13, p=0.023)$, sometimes $(\mathrm{aPR}=1.30, p<0.001)$ and always $(\mathrm{aPR}=1.54, p<0.001)$ lonely had a heightened risk of having hypertension than those who never felt lonely. Consumption of vegetables on $<4$ days a week was also associated with higher risk, with a significant association among those who consumed vegetables for 1-3 days. Those individuals who previously drank alcohol had a higher risk of having hypertension $(\mathrm{aPR}=1.24, p<0.001)$.

The results also showed that those living in the eastern region $(\mathrm{aPR}=0.87, p=0.002)$ and those working ( $\mathrm{aPR}=0.93, p=0.04$ ) had reduced risk. The associations for most of the 
JHR

35,6

\begin{tabular}{|c|c|c|c|c|}
\hline Variables & $n(\%)$ & $\begin{array}{l}\text { Nonhypertensive } \mathrm{n}(\%) \\
n=25673\end{array}$ & $\begin{array}{c}\text { Hypertensive } n(\%) \\
n=5216\end{array}$ & $p$-value ${ }^{1}$ \\
\hline \multicolumn{5}{|l|}{ Demographic } \\
\hline $\begin{array}{l}\text { Age (years) } \\
18-24 \\
25-34 \\
35-44 \\
45-54 \\
55-64 \\
>64 \\
\text { Missing/not reported }\end{array}$ & $\begin{array}{l}5853(18.9) \\
7911(25.6) \\
6206(20.1) \\
5057(16.4) \\
3639(11.8) \\
2221(7.2) \\
1(0.1)\end{array}$ & $\begin{array}{l}5445(21.2) \\
6903(26.9) \\
5015(19.5) \\
3935(15.3) \\
2765(10.8) \\
1609(6.3) \\
1(0.1)\end{array}$ & $\begin{array}{c}408(7.8) \\
1008(19.3) \\
1191(22.8) \\
1122(21.5) \\
874(16.8) \\
612(11.7) \\
1(0.1)\end{array}$ & $<0.001$ \\
\hline $\begin{array}{l}\text { Gender } \\
\text { Male } \\
\text { Female }\end{array}$ & $\begin{array}{l}14132(45.8) \\
16757(54.3)\end{array}$ & $\begin{array}{l}12181(47.5) \\
13492(52.6)\end{array}$ & $\begin{array}{l}1951(37.4) \\
3265(62.6)\end{array}$ & $<0.001$ \\
\hline $\begin{array}{l}\text { Marital status } \\
\text { Not married } \\
\text { Married } \\
\text { Previously married }{ }^{2} \\
\text { Missing/not reported }\end{array}$ & $\begin{array}{c}5047(16.3) \\
22843(74.0) \\
2966(9.6) \\
33(0.1)\end{array}$ & $\begin{array}{r}4707(18.3) \\
18633(72.6) \\
2306(8.9) \\
27(0.1)\end{array}$ & $\begin{array}{r}340(6.5) \\
4210(80.7) \\
660(12.7) \\
6(0.12)\end{array}$ & $<0.001$ \\
\hline \multicolumn{5}{|l|}{ Socioeconomic } \\
\hline $\begin{array}{l}\text { Education level } \\
\text { No education } \\
\text { Primary } \\
\text { >High school } \\
\text { Monastic/non-formal education } \\
\text { Missing/not reported }\end{array}$ & $\begin{array}{r}15965(51.7) \\
3732(12.1) \\
7545(24.3) \\
3524(11.4) \\
124(0.4)\end{array}$ & $\begin{array}{r}12816(49.9) \\
3102(12.1) \\
6752(26.3) \\
2898(11.3) \\
105(0.4)\end{array}$ & $\begin{array}{c}3149(60.4) \\
630(12.1) \\
793(15.2) \\
625(12.0) \\
19(0.4)\end{array}$ & $<0.001$ \\
\hline $\begin{array}{l}\text { Work status } \\
\text { Not working } \\
\text { Working } \\
\text { Missing/not reported }\end{array}$ & $\begin{array}{c}15480(50.1) \\
15073(48.8) \\
336(1.1)\end{array}$ & $\begin{array}{c}12642(49.2) \\
12739(49.6) \\
292(1.1)\end{array}$ & $\begin{array}{c}2838(54.4) \\
2334(44.8) \\
44(0.8)\end{array}$ & $<0.001$ \\
\hline $\begin{array}{l}\text { Wealth index } \\
\text { Poorest } \\
\text { Second } \\
\text { Middle } \\
\text { Fourth } \\
\text { Richest }\end{array}$ & $\begin{array}{l}5964(19.3) \\
6373(20.6) \\
6689(21.7) \\
6303(20.4) \\
5560(18.0)\end{array}$ & $\begin{array}{l}5201(20.3) \\
5326(20.8) \\
5524(21.5) \\
5090(19.8) \\
4532(17.7)\end{array}$ & $\begin{array}{r}763(14.6) \\
1047(20.1) \\
1165(22.3) \\
1213(23.3) \\
1028(19.7)\end{array}$ & $<0.001$ \\
\hline \multicolumn{5}{|l|}{ Geographic } \\
\hline $\begin{array}{l}\text { Place of residence } \\
\text { Rural } \\
\text { Urban }\end{array}$ & $\begin{array}{r}24074(77.9) \\
6815(22.1)\end{array}$ & $\begin{array}{r}20072(78.2) \\
5601(21.8)\end{array}$ & $\begin{array}{l}4002(76.7) \\
1214(23.3)\end{array}$ & 0.021 \\
\hline $\begin{array}{l}\text { Region of residence } \\
\text { Western } \\
\text { Central } \\
\text { Eastern }\end{array}$ & $\begin{array}{r}10386(33.6) \\
11806(38.2) \\
8697(28.2)\end{array}$ & $\begin{array}{l}8624(33.6) \\
9766(38.0) \\
7283(28.4)\end{array}$ & $\begin{array}{l}1762(33.8) \\
2040(39.1) \\
1414(27.1)\end{array}$ & 0.150 \\
\hline \multicolumn{5}{|l|}{ Health } \\
\hline $\begin{array}{l}\text { Diabetes status } \\
\text { No } \\
\text { Yes } \\
\text { Missing/not reported }\end{array}$ & $\begin{array}{c}30388 \text { (98.4) } \\
497(1.6) \\
4(0.1)\end{array}$ & $\begin{array}{c}25456(99.2) \\
213(0.8) \\
4(0.1)\end{array}$ & $\begin{array}{c}4932(94.6) \\
284(5.4) \\
0\end{array}$ & $<0.001$ \\
\hline
\end{tabular}

Table 1.

Characteristics of sample and distribution of hypertension by demographic, socioeconomic, geographic, health and Missing/not reported behavioral risk factors $(n=30,889)$

Eastern

Health

Diabetes status

No
$14132(45.8)$

$16757(54.3)$

5047 (16.3)

$22843(74.0)$

$966(9.6)$

Previously married ${ }^{2}$

not not reported

Education level

No education

$\geq$ High school

Missing/not reported

Work status

Not working

Working

ing/ not reported

Wealth index

Middle

Fourth

Richest

24074 (77.9)

$10386(33.6)$

$11806(38.2)$

498 (1.6)
$4(0.1)$

$4(0.1)$
$3102(12.1)$

898 (11.3)

(4)

5201 (20.3)

$5326(20.8)$

$5524(21.5)$

5090 (19.8)

4532 (17.7)

20072 (78.2)

8624 (33.6)

9766 (38.0)

$2040(39.1)$

$1414(27.1)$

4932 (94.6)

(5.4)

(continued) 


\begin{tabular}{|c|c|c|c|c|c|}
\hline Variables & $n(\%)$ & $\begin{array}{c}\text { Nonhypertensive } \mathrm{n}(\%) \\
n=25673\end{array}$ & $\begin{array}{c}\text { Hypertensive } n(\%) \\
n=5216 \\
\end{array}$ & $p$-value ${ }^{1}$ & $\begin{array}{l}\text { Risk factors of } \\
\text { hypertension }\end{array}$ \\
\hline Feel lonely & & & & $<0.001$ & \\
\hline Never & $19393(62.8)$ & 16514 (64.3) & $2879(55.2)$ & & \\
\hline Rarely & 4518 (14.6) & 3723 (14.5) & 795 (15.2) & & \\
\hline Sometimes & $6629(21.5)$ & $5196(20.2)$ & $1433(27.5)$ & & \\
\hline Always & $326(1.02)$ & $221(0.9)$ & $105(2.0)$ & & 545 \\
\hline Missing/not reported & $23(0.1)$ & $19(0.1)$ & $4(0.1)$ & & \\
\hline Health service use & & & & $<0.001$ & \\
\hline No & 11105 (36.0) & 9884 (38.5) & $1221(23.4)$ & & \\
\hline Yes & 19751 (63.9) & 15758 (61.4) & 3993 (76.6) & & \\
\hline Missing/not reported & $33(0.1)$ & $31(0.1)$ & $2(0.1)$ & & \\
\hline \multicolumn{6}{|l|}{ Behavioral } \\
\hline $\begin{array}{l}\text { Vegetable servings per week } \\
\text { (days) }\end{array}$ & & & & 0.067 & \\
\hline 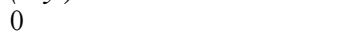 & $930(3.0)$ & $770(3.0)$ & $160(3.1)$ & & \\
\hline $1-3$ & $7414(24.0)$ & $6092(23.7)$ & $1322(25.4)$ & & \\
\hline $4-5$ & 9963 (32.3) & $8330(32.5)$ & 1633 (31.3) & & \\
\hline $6-7$ & 11709 (37.9) & 9739 (37.9) & $1970(37.8)$ & & \\
\hline Missing/not reported & $873(2.8)$ & $742(2.9)$ & $131(2.5)$ & & \\
\hline \multicolumn{4}{|l|}{ Fruit servings per week (days) } & 0.001 & \\
\hline 0 & $17189(55.7)$ & $14421(56.2)$ & $2768(53.1)$ & & \\
\hline $1-3$ & $8014(25.9)$ & 6599 (25.7) & 1415 (27.13) & & \\
\hline $4-5$ & $2666(8.6)$ & $2190(8.5)$ & $476(9.1)$ & & \\
\hline $6-7$ & $2089(6.8)$ & $1698(6.6)$ & $391(7.5)$ & & \\
\hline Missing/not reported & $931(3.0)$ & $765(3.0)$ & $166(3.2)$ & & \\
\hline & $<0.001$ & \\
\hline$\geq 300$ mins per week & $13761(44.6)$ & 11617 (45.3) & $2144(41.1)$ & & \\
\hline $150-<300$ mins per week & $1851(6.0)$ & $1581(6.2)$ & $270(5.2)$ & & \\
\hline$<150$ mins per week & $15276(49.4)$ & $12474(48.6)$ & $2802(53.7)$ & & \\
\hline Missing/not reported & $1(0.1)$ & $1(0)$ & 0 & & \\
\hline \multicolumn{4}{|l|}{ Walk and bicycle } & 0.002 & \\
\hline Yes & 21460 (69.5) & $17940(70.0)$ & 3520 (67.5) & & \\
\hline No & 9419 (30.5) & $7724(30.1)$ & 1695 (32.5) & & \\
\hline Missing/not reported & $10(0.1)$ & $9(0.1)$ & $1(0.1)$ & & \\
\hline \multicolumn{4}{|l|}{ Ever smoked } & $<0.001$ & \\
\hline No & $26125(84.6)$ & $21805(84.9)$ & $4320(82.8)$ & & \\
\hline Yes & 4758 (15.4) & $3862(15.0)$ & $896(17.2)$ & & \\
\hline Missing/not reported & $6(0.1)$ & $6(0.1)$ & $0(0)$ & & \\
\hline \multicolumn{4}{|l|}{ Smokeless tobacco } & 0.021 & \\
\hline No & 15538 (50.3) & 12996 (50.6) & $2542(48.7)$ & & \\
\hline Yes & $15326(49.6)$ & 12654 (49.3) & $2672(51.2)$ & & \\
\hline Missing/not reported & $25(0.1)$ & $23(0.1)$ & $2(0.1)$ & & \\
\hline \multicolumn{4}{|l|}{ Alcohol use } & $<0.001$ & \\
\hline Nondrinker & $16202(52.5)$ & $13586(52.9)$ & $2616(50.2)$ & & \\
\hline Past drinker & 3671 (11.9) & $2774(10.8)$ & 897 (17.2) & & \\
\hline$\leq 3$ days a month & 3531 (11.4) & 2931 (11.4) & $600(11.5)$ & & \\
\hline $1-4$ days per week & 2999 (9.7) & $2577(10.0)$ & $422(8.1)$ & & \\
\hline$\geq 5$ days per week & 4452 (14.4) & 3777 (14.7) & $675(12.9)$ & & \\
\hline Missing/not reported & $34(0.1)$ & $28(0.1)$ & $6(0.1)$ & & \\
\hline \multicolumn{5}{|c|}{ Note(s): ${ }^{1}$ Chi-square test of significance; ${ }^{2}$ Includes divorced, separated and widowed } & Table 1. \\
\hline
\end{tabular}


JHR

35,6

\begin{tabular}{|c|c|c|c|c|}
\hline Variables & PR $(95 \%$ CI $)$ & $p$-value & aPR $(95 \%$ CI) & $p$-value \\
\hline \multicolumn{5}{|l|}{ Demographic } \\
\hline $\begin{array}{l}\text { Age (ref: 18-24) } \\
25-34 \\
35-44 \\
45-54 \\
55-64 \\
>64\end{array}$ & $\begin{array}{l}1.81(1.60-2.05) \\
2.66(2.25-3.14) \\
3.21(2.79-3.69) \\
3.51(2.98-4.13) \\
4.02(3.50-4.61)\end{array}$ & $\begin{array}{l}<0.001 \\
<0.001 \\
<0.001 \\
<0.001 \\
<0.001\end{array}$ & $\begin{array}{l}1.46(1.25-1.70) \\
2.03(1.64-2.51) \\
2.49(2.07-3.00) \\
2.64(2.19-3.18) \\
3.17(2.59-3.88)\end{array}$ & $\begin{array}{l}<0.001 \\
<0.001 \\
<0.001 \\
<0.001 \\
<0.001\end{array}$ \\
\hline $\begin{array}{l}\text { Gender (ref: Male) } \\
\text { Female }\end{array}$ & $1.42(1.34-1.50)$ & $<0.001$ & $1.33(1.23-1.43)$ & $<0.001$ \\
\hline $\begin{array}{l}\text { Marital status (ref: not married) } \\
\text { Married } \\
\text { Previously married }^{1}\end{array}$ & $\begin{array}{l}2.76(2.36-3.22) \\
3.24(2.78-3.79)\end{array}$ & $\begin{array}{l}<0.001 \\
<0.001\end{array}$ & $\begin{array}{l}1.53(1.22-1.93) \\
1.35(1.09-1.67)\end{array}$ & $\begin{array}{r}<0.001 \\
0.006\end{array}$ \\
\hline $\begin{array}{l}\text { Socioeconomic } \\
\text { Education level (ref: } \geq \text { High schoo } \\
\text { No education } \\
\text { Primary } \\
\text { Monastic/non-formal education }\end{array}$ & $\begin{array}{l}1.82(1.68-1.99) \\
1.56(1.37-1.77) \\
1.60(1.39-1.82)\end{array}$ & $\begin{array}{l}<0.001 \\
<0.001 \\
<0.001\end{array}$ & $\begin{array}{l}1.18(1.05-1.32) \\
1.26(1.10-1.45) \\
1.34(1.19-1.52)\end{array}$ & $\begin{array}{r}0.006 \\
0.001 \\
<0.001\end{array}$ \\
\hline $\begin{array}{l}\text { Work status (ref: Not working) } \\
\text { Working }\end{array}$ & $0.82(0.78-0.87)$ & $<0.001$ & $0.93(0.87-0.99)$ & 0.045 \\
\hline $\begin{array}{l}\text { Wealth index (ref: Poorest) } \\
\text { Second } \\
\text { Middle } \\
\text { Fourth } \\
\text { Richest }\end{array}$ & $\begin{array}{l}1.33(1.13-1.56) \\
1.42(1.18-1.71) \\
1.62(1.35-1.93) \\
1.44(1.18-1.77)\end{array}$ & $\begin{array}{r}0.001 \\
<0.001 \\
<0.001 \\
0.001\end{array}$ & $\begin{array}{l}1.29(1.14-1.48) \\
1.43(1.20-1.69) \\
1.73(1.48-2.03) \\
1.65(1.37-1.99)\end{array}$ & $\begin{array}{l}<0.001 \\
<0.001 \\
<0.001 \\
<0.001\end{array}$ \\
\hline
\end{tabular}

\section{Geographic}

Place of residence (ref: Urban)

Rural

$1.07(0.98-1.17) \quad 0.126$

Region of residence (ref: Western)

Central

Eastern

$1.02(0.94-1.11)$

$0.91(0.80-1.03)$

0.657

0.113

$1.02(0.93-1.11)$

0.737

Health

Diabetes status (ref: No)

Yes

$3.30(2.96-3.68)$

Feel lonely (ref: Never)

Rarely

Sometimes

Always

$1.21(1.10-1.32)$

$1.47(1.38-1.58)$

$1.93(1.65-2.25)$

$<0.001$

$<0.001$

$0.87(0.80-0.95)$

0.002

Health service use (ref: No)

Yes

$1.78(1.66-1.91)$

$<0.001$

$1.59(1.48-1.71)$

$<0.001$

\section{Behavioral}

Table 2.

Vegetable servings per week (ref: 6-7 days)

Risk factors associated $4-5$

with hypertension in 1-3

the bivariate and

0

$0.98(0.93-1.04)$

$1.08(1.01-1.16)$

0.516

0.020

$0.98(0.92-1.04)$

0.523

$1.15(0.92-1.42)$

0.216 


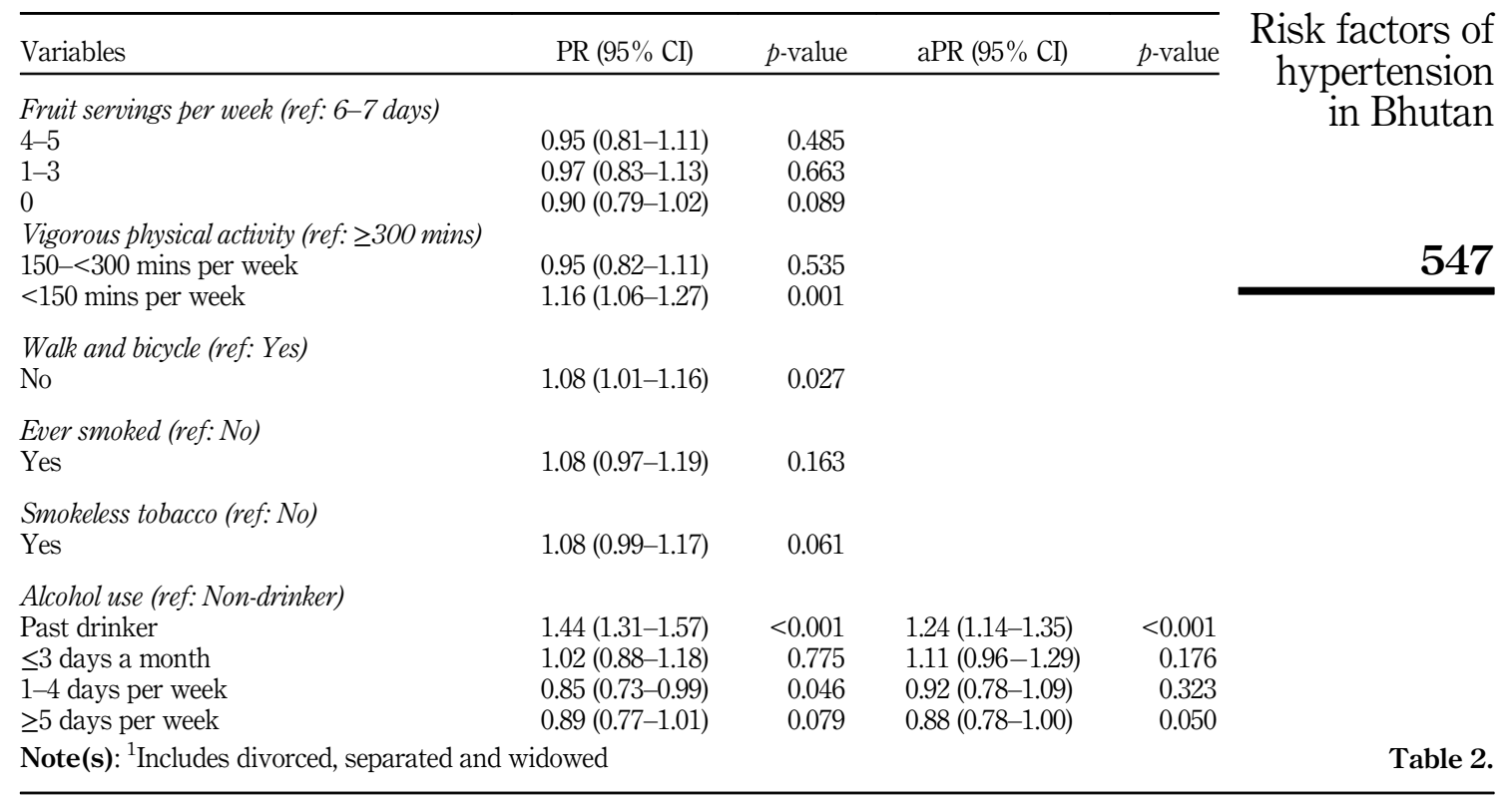

variables were in similar directions in the analysis that was stratified by region of residence (Table 3). The common factors associated with hypertension across the regions were age, gender, education, wealth status, diabetes status, loneliness and health service use. However, marital status and vegetable consumption were significantly associated with hypertension only in the western and central regions, whereas the association for alcohol use was only significant in the eastern and central regions. Working status was associated with hypertension only in the western region.

\section{Discussion}

This study examined the factors associated with hypertension in Bhutan using a nationally representative dataset. The prevalence of self-reported hypertension among adults was $17 \%$ in 2012. The exclusion of participants who were $<18$ years in our study could have led to the nominal difference when compared to the prevalence in the 2012 NHS report (16\%). The 2014 World Health Organization (WHO)'s STEPwise survey conducted in Bhutan, however, reported a much higher rate of $35.7 \%$. The heterogeneity in the methodology between the surveys, especially in assessing hypertension status, could have led to this variation. Such a gap in self-reported and diagnosed hypertension was also documented in a previous study in urban Bhutan [8]. We found that older age, being female, being married and previously married, low education, higher economic status and residing in the western region were the factors associated with having hypertension. The use of health services, past alcohol use, feeling lonely and having diabetes was also associated with increased risk.

The escalating risk of hypertension with increasing age found in our study is consistent with the evidence in the literature [16-19]. The walls of the aorta and arteries become stiff with older age contributing to higher prevalence among older people [17]. Because age is a nonmodifiable factor, the focus needs to be on healthy aging policies that also include the promotion of healthy diet and weight, physical activity and improving the features of the built and social environment to enable lifestyle changes [20]. Interventions to promote healthy aging becomes more relevant given the changing population age structure with increasing 


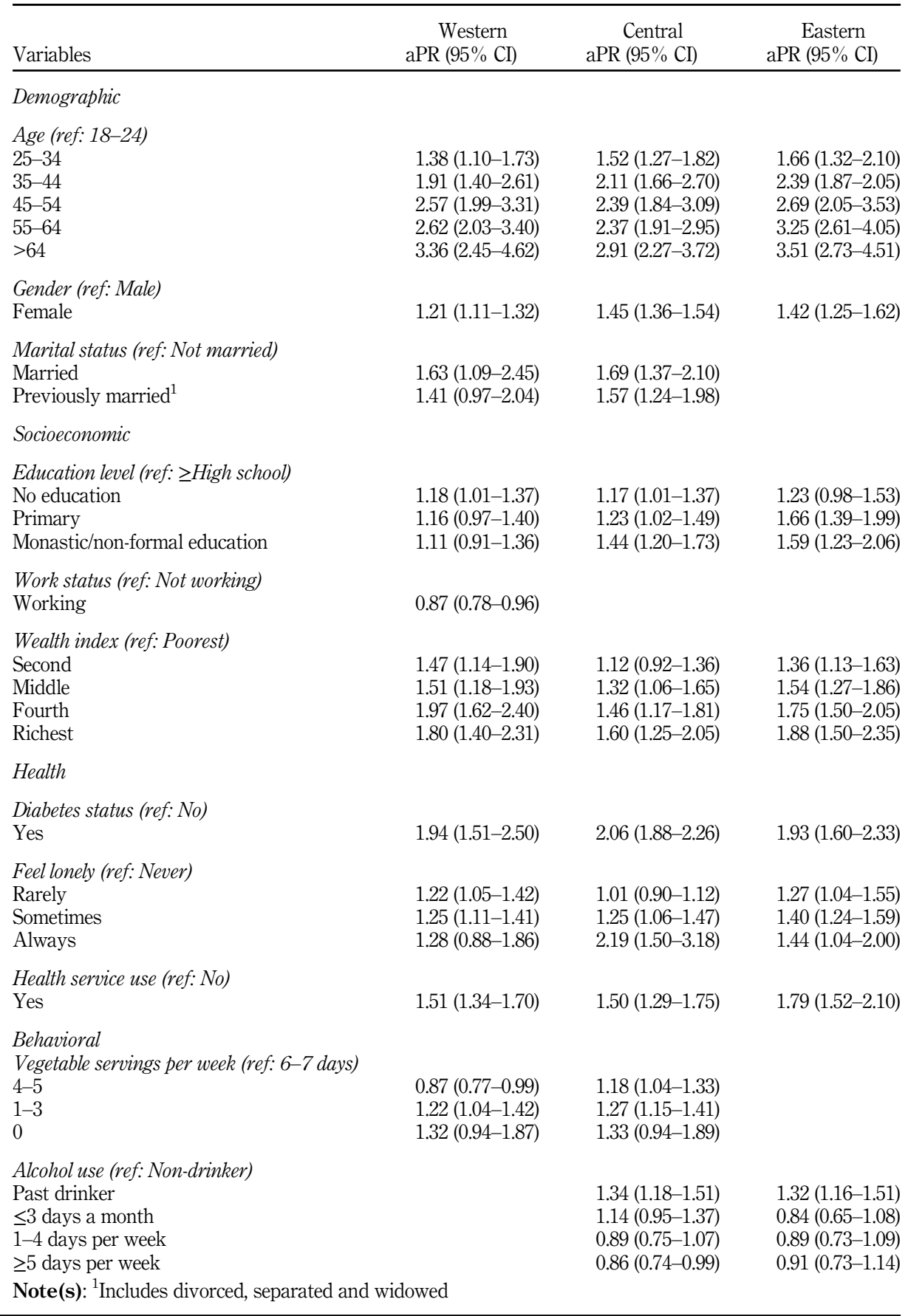

Table 3. with hypertension by regions of residence
Risk factors associated

\section{8}

548

35

25-34

$45-54$

$55-64$

Gender (ref: Male)

Marital status (ref: Not married)

Married

Previously married

$1.18(1.01-1.37)$

$1.16(0.97-1.40)$

$1.11(0.91-1.36)$

$1.23(1.02-1.49)$

$1.44(1.20-1.73)$

$1.66(1.39-1.99)$

$1.59(1.23-2.06)$

Work status (ref: Not working)

Working

$1.12(0.92-1.36)$

$1.32(1.06-1.65)$

$1.46(1.17-1.81)$

$1.54(1.27-1.86)$

Middle

Richest

Health

Diabetes status (ref: No)

Feel lonely (ref: Never)

Sometimes

$1.22(1.04-1.42)$

$127(1.15-1.41)$

$33(0.94-1.89)$

$1.34(1.18-1.51)$

(0.95-1.37)

$0.89(0.75-1.07)$

$0.89(0.73-1.09)$

$1-4$ days per week

Note(s): ${ }^{1}$ Includes divorced, separated and widowed 
life expectancy and declining birth rates [11]. This will undoubtedly lead to greater rates of hypertension and associated chronic diseases in the older population. Females were more likely to have hypertension than men. This aligns with some studies [18, 21, 22]. Higher prevalence of overweight and obesity, lower physical activity levels [9] and consumption of energy-dense foods among females could be some possible explanations. In another similar to the finding in a study (23), those study [23], those married and previously married also had a higher risk of hypertension. Although those married and previously married may be much older, putting them at an increased risk, the literature suggests married individuals are healthier, whereas those previously married (widowed/divorced/separated) have the poorest health followed by those who are single [24]. The greater risk among married individuals in this study may also be a statistical artifact and represent other correlations.

We found that those with low education and monastic and or nonformal education had higher hypertension risk. This may reflect a lack of health awareness among these groups. Those with low education may be socioeconomically disadvantaged, which include low income, unemployment, poor job conditions, job strain, which is shown to be associated with hypertension [25]. This is partly supported by the finding of a reduced probability of hypertension among working individuals in our study as well as a study from Bangladesh [22]. Employed individuals may also be better educated. The sedentary lifestyle and consumption of a less healthy diet in monastic institutions in Bhutan might have also contributed to the higher risk in this group [13]. Moreover, the majority of nonformal education learners were females $(>70 \%)$, and our data also show increased hypertension risk among females. Health education programs and the formulation of health education modules into monastic and nonformal learning programs may increase awareness of disease prevention and potentially motivate health service use and lifestyle changes.

Consistent with some studies [16, 22, 23], we found that hypertension risk was higher among those from wealthier households. Limited physical activity and greater exposure and subsequent consumption of less healthy diets attributable to higher purchasing power might explain this pattern. Results show that those who ate fewer vegetables had a heightened risk of hypertension. Fruit and vegetable consumption have been shown to prevent hypertension, although the effect seems stronger for fruit consumption [26, 27]. High alcohol intake is an important risk factor for hypertension [17, 19]. Aligning with other studies [28, 29], the results showed former drinkers had an increased risk of hypertension. Although the associations were not strong, current drinkers seemingly had reduced risk. Owing to health problems, including those related to hypertension, former drinkers might have quit drinking, and separating former from current drinkers could have led to selecting a relatively healthy current drinker sample [29] in this study. The high alcohol consumption prevalence (50\% in men and 33\% in women) and related mortality in Bhutan call for urgent public health interventions [9, 11].

Our finding suggests that those living in the eastern part of the country are less likely to have hypertension. Eastern Bhutan is seemingly less developed and urbanized [30], and the majority of the people live on sustenance farming that might enable people to be active physically. Additionally, junk food availability and consumption, also an outcome of urbanization, may be comparatively less in the east. Studies show that generally urban populations are at much higher risk of hypertension [4, 16, 22]. However, a low health service utilization and awareness in eastern Bhutan might have led to a reduced likelihood of being diagnosed, and the result may also reflect the impact of migration of the eastern population to the western and central regions [6]. Similar to another study [18], we found that health service use was positively associated with hypertension. Accessibility to health services can result in increased health education that, in turn, can encourage health screening. However, it is conceivable that those with health conditions may be also the ones utilizing health services.

The analysis stratified by region of residence showed that marital status, working status and vegetable intake were not significantly associated with hypertension in the eastern

\section{Risk factors of hypertension in Bhutan}


JHR

35,6

region. This potentially suggests that other common factors identified may be more important in influencing hypertension in the east than these factors. The analysis showed that the association for alcohol was not statistically significant in the western region. The relatively higher prevalence of alcohol use in the central (51.3\%) and eastern $(56.9 \%)$ regions compared to the western (35.4\%) region may explain this finding.

We found increasing intensity of loneliness to be significantly associated with increased risk of hypertension, indicating a plausible dose-response relationship. Loneliness is an important risk factor for heightened blood pressure levels [25, 31, 32]. Loneliness may influence hypertension through elevated total peripheral resistance (TPR) levels, the main cause of high blood pressure, which has been found to be persistently increased in lonely individuals [32]. Changes in cortisol regulation and endothelial function and excess apprehension for one's safety and security with others have also been posited to be some probable pathways [31]. Interventions to enhance social skills and support, creating opportunities for social interactions, meditation and cognitive behavioral therapy may help reduce the adverse health impact of loneliness [32]. As expected and evident in some other studies [17, 22], diabetes also emerged to be associated with hypertension in our study.

\section{Strengths and limitations}

The strengths of this study include a large nationally representative sample and a high response rate. The use of the survey data analysis method to account for the complex survey design effect also lends the results credible.

Nevertheless, the study had several limitations. First, the cross-sectional design of the study precludes drawing any causal inferences. The results are prone to recall bias since demographic and health surveys are retrospective in nature. Similarly, all the measures, including the dependent variable, were obtained through interviews and thus could have been underreported. This might have potentially underestimated the prevalence and associations identified in this study. Finally, owing to the nonavailability of data in the NHS, we could not assess the influence of some factors such as body mass index and sodium intake, which are shown to be more important predictors of hypertension [4, 16-18, 21, 22, 26]. The intake of salt among the Bhutanese population was found to be almost two times that of the WHO-recommended quantity [9]. Future studies need to use better measures and also investigate those factors not examined in this study.

\section{Conclusions}

Hypertension is a significant public health problem in Bhutan, and one-sixth of the population had increased blood pressure. Finding shows age, gender, marital status, wealth status, employment, education, the region of residence, alcohol use, diabetes status, health service use, loneliness and low vegetable intake to be associated with the risk of having hypertension. The findings may help inform targeted policy investments for different sections of the population to reduce the hypertension burden.

Potential approaches to lower the hypertension burden include increasing awareness on prevention, reducing harmful alcohol use and gender-focused prevention interventions, including screening programs. Lifestyle modification programs such as increasing physical activity, healthy dietary intake and weight loss should form an integral part of the national strategy. Strategies to enhance health utilization can also identify individuals at risk and facilitate early detection. The health sector, in collaboration with other relevant sectors such as urban and transport planning agencies, needs to develop and implement plans aimed to create or change the physical and social environment that promotes health and enable lifestyle changes. Similar studies are required in the future to better understand the changing epidemiology of hypertension in Bhutan. Targeted interventions are urgently needed to reduce the growing hypertension epidemic and its health and economic consequences. 


\section{References}

1. World Health Organization [WHO]. A global brief on hypertension: silent killer, global public health crisis. Available from: https:/www.who.int/cardiovascular_diseases/publications/global_ brief_hypertension/en (accessed 172019 November).

2. Lim SS, Vos T, Flaxman AD, Danaei G, Shibuya K, Adair-Rohani H, et al. A comparative risk assessment of burden of disease and injury attributable to 67 risk factors and risk factor clusters in 21 regions, 1990-2010: a systematic analysis for the Global Burden of Disease Study 2010. Lancet. 2012 Dec; 380(9859): 2224-60. doi: 10.1016/S0140-6736(12)61766-8.

3. Zhou B, Bentham J, Di Cesare M, Bixby H, Danaei G, Cowan MJ, et al. Worldwide trends in blood pressure from 1975 to 2015: a pooled analysis of 1479 population-based measurement studies with 19.1 million participants. Lancet. 2017 Jan; 389(10064): 37-55. doi: 10.1016/S0140-6736(16)31919-5.

4. Neupane D, McLachlan CS, Sharma R, Gyawali B, Khanal V, Mishra SR, et al. Prevalence of hypertension in member countries of South Asian Association for Regional Cooperation (SAARC): systematic review and meta-analysis. Medicine (Baltim.). 2014 Sep; 93(13): e74. doi: 10.1097/MD. 0000000000000074 .

5. World Health Organization [WHO]. High blood pressure: global and regional overview. New Delhi: WHO; 2013.

6. Thinley S, Tshering P, Wangmo K, Wangchuk N, Dorji T, Tobgay T, et al. The Kingdom of Bhutan health system review. New Delhi: WHO; 2017. Available from: https:/apps.who.int/iris/ handle/10665/255701 (accessed 172019 November).

7. Ministry of Health. National health survey report 2012. Ministry of Health, Royal Government of Bhutan. Available from: http://www.health.gov.bt/publications/national-health-survey/ (accessed 172019 November).

8. Giri BR, Sharma KP, Chapagai RN, Palzom D. Diabetes and hypertension in urban bhutanese men and women. Indian J Community Med. 2013 Jul; 38(3): 138-43. doi: 10.4103/0970-0218.116349.

9. World Health Organization [WHO]. National survey for noncommunicable disease risk factors and mental health using WHO STEPS approach in Bhutan - 2014. Available from: https://www.who. int/ncds/surveillance/steps/Bhutan_2014_STEPS_Report.pdf (accessed 172019 November).

10. Ministry of Health. Annual health bulletin 2015. Ministry of Health, Royal Government of Bhutan. Available from: http://www.health.gov.bt/publications/annual-health-bulletins/ (accessed 172019 November).

11. Ministry of Health. Annual health bulletin 2018. Ministry of Health, Royal Government of Bhutan. Available from: http://www.health.gov.bt/publications/annual-health-bulletins/ (accessed 172019 November).

12. Wangdi T. Burden, determinants and control of hypertension: a Bhutanese perspective. Regional Health Forum. 2013; 17(1): 20-5.

13. Tshering N, Somrongthong R. Prevalence and determinants of hypertension among Bhutanese monks in Tashi-Choe-Dzong, Thimphu, Bhutan. J Health Res. 2011; 25(2): 97-9.

14. Fekedulegn D, Andrew M, Violanti J, Hartley T, Charles L, Burchfiel C. Comparison of statistical approaches to evaluate factors associated with metabolic syndrome. J. Clin. Hypertens $2010 \mathrm{May}$; 12(5): 365-73. doi: 10.1111/j.1751-7176.2010.00264.x.

15. Barros AJ, Hirakata VN. Alternatives for logistic regression in cross-sectional studies: an empirical comparison of models that directly estimate the prevalence ratio. BMC Med Res Methodol. 2003 Oct; 3: 21. doi: 10.1186/1471-2288-3-21.

16. Hasan M, Sutradhar I, Akter T, Das Gupta R, Joshi H, Haider MR, et al. Prevalence and determinants of hypertension among adult population in Nepal: data from Nepal Demographic and Health Survey 2016. PLoS ONE. 2018; 13(5): e0198028. doi: 10.1371/journal.pone.0198028.

17. Abebe SM, Berhane Y, Worku A, Getachew A. Prevalence and associated factors of hypertension: a crossectional community based study in northwest Ethiopia. PLoS ONE. 2015; 10(4): e0125210. doi: 10.1371/journal.pone.0125210.

Risk factors of hypertension in Bhutan 
JHR 35,6

18. Peltzer K, Pengpid S. The prevalence and social determinants of hypertension among adults in Indonesia: a cross-sectional population-based national survey. Int J Hypertens. 2018; 2018: 5610725. doi: 10.1155/2018/5610725.

19. Lee SH, Kim YS, Sunwoo S, Huh BY. A retrospective cohort study on obesity and hypertension risk among Korean adults. J Korean Med Sci. 2005 Apr; 20(2): 188-95. doi: 10.3346/jkms.2005.20. 2.188 .

20. Leal C, Chaix B. The influence of geographic life environments on cardiometabolicrisk factors: a systematic review, a methodological assessment and a research agenda. Obes Rev. 2011 Mar; 12(3): 217-30. doi: 10.1111/j.1467-789X.2010.00726.x.

21. Malekzadeh MM, Etemadi A, Kamangar F, Khademi H, Golozar A, Islami F, et al. Prevalence, awareness and risk factors of hypertension in a large cohort of Iranian adult population. J Hypertens. 2013 Jul; 31(7): 1364-71. doi: 10.1097/HJH.0b013e3283613053.

22. Chowdhury MA, Uddin MJ, Haque MR, Ibrahimou B. Hypertension among adults in Bangladesh: evidence from a national cross-sectional survey. BMC Cardiovasc Disord. 2016 Jan; 16: 22. doi: 10. 1186/s12872-016-0197-3.

23. Singh S, Shankar R, Singh GP. Prevalence and associated risk factors of hypertension: a crosssectional study in urban Varanasi. Int J Hypertens. 2017; 2017: 5491838. doi: 10.1155/2017/5491838.

24. Verbrugge LM. Marital status and health. J Marriage Fam. 1979; 41(2): 267-85.

25. Cuffee Y, Ogedegbe C, Williams NJ, Ogedegbe G, Schoenthaler A. Psychosocial risk factors for hypertension: an update of the literature. Curr Hypertens Rep. 2014 Oct; 16(10): 483. doi: 10.1007/ s11906-014-0483-3.

26. Zhao D, Qi Y, Zheng Z, Wang Y, Zhang XY, Li HJ, et al. Dietary factors associated with hypertension. Nat Rev Cardiol. 2011 Jul; 8(8): 456-65. doi: 10.1038/nrcardio.2011.75.

27. Borgi L, Muraki I, Satija A, Willett WC, Rimm EB, Forman JP. Fruit and vegetable consumption and the incidence of hypertension in three prospective cohort studies. Hypertension. 2016 Feb; 67(2): 288-93. doi: 10.1161/HYPERTENSIONAHA.115.06497.

28. Chan YY, Teh CH, Lim KK, Lim KH, Yeo PS, Kee CC, et al. Lifestyle, chronic diseases and selfrated health among Malaysian adults: results from the 2011 National Health and Morbidity Survey (NHMS). BMC Publ. Health. 2015 Aug; 15: 754. doi: 10.1186/s12889-015-2080-z.

29. Liang W, Chikritzhs T. The association between alcohol exposure and self-reported health status: the effect of separating former and current drinkers. PLoS ONE. 2013; 8(2): e55881. doi: 10.1371/ journal.pone.0055881.

30. Eastern Bhutan must develop. Kuensel [internet]. 2016 March 4. Available from: http://www. kuenselonline.com/eastern-bhutan-must-develop/ (accessed 172019 November).

31. Hawkley LC, Thisted RA, Masi CM, Cacioppo JT. Loneliness predicts increased blood pressure: 5-year cross-lagged analyses in middle-aged and older adults. Psychol. Aging. 2010 Mar; 25(1): 132-41. doi: 10.1037/a0017805.

32. Xia N, Li H. Loneliness, social isolation, and cardiovascular health. Antioxid Redox Signal. 2018; 28(9): 837-51. doi: 10.1089/ars.2017.7312.

\section{Corresponding author}

Tashi Dendup can be contacted at: taseedee@gmail.com

For instructions on how to order reprints of this article, please visit our website:

www.emeraldgrouppublishing.com/licensing/reprints.htm

Or contact us for further details: permissions@emeraldinsight.com 